\title{
PREVALÊNCIA DE Echinococcus granulosus (BATSCH, 1786) EM CÃES URBANOS ERRANTES DO MUNICÍPIO DE DOM PEDRITO (RS), BRASIL
}

\author{
PREVALENCE OF Echinococcus granulosus (BATSCH, 1786) IN URBAN STRAY DOGS FROM DOM \\ PEDRITO IN THE STATE OF RIO GRANDE DO SUL, BRAZIL
}

\author{
Adriane Nunes Hoffmann ${ }^{1}$ Ramiro Malgor ${ }^{2}$ Mário Luiz de la Rue ${ }^{3}$
}

\section{RESUMO}

Echinococcus granulosus é um dos parasitas mais importantes envolvidos em zoonoses de municípios próximos a fronteira do Rio grande do Sul com a Argentina e Uruguai. Amostras de 65 cães urbanos errantes do município de Dom Pedrito foram analisadas por meio de três técnicas: purgação pelo bromidrato de arecolina para visualização da presença do parasito; ensaio de imunoadsorção enzimática (ELISA), para detecção de coproantígenos, imunofluorescência indireta (IFI), para detecção de anticorpos séricos contra E. granulosus. Destes cães, 7,7\% (5/65) apresentaram o parasita nas fezes, 10,8 (7/65) coproantígenos e 13,8\% (9/65) anticorpos séricos contra o cestódeo. Conclui-se que a equinococose canina, no meio urbano, pode representar um sério problema à saúde pública, devido ao risco de hidatidose humana.

Palavras-chave: Echinococcus granulosus, Dom Pedrito, prevalência, cães urbanos errantes.

\section{SUMMARY}

Echinococcus granulosus is the one of the most important parasites involved in zoonosis in the State of Rio Grande do Sul, in cities near the Argentinian and Uruguayian border. Sixty-five samples of urban stray dogs from Dom Pedrito county were analyzed by three techniques: purgation by arecoline hydrobromide, to verify the presence of the parasite; enzymelinked immunosorbent assay test (ELISA), to detect the coproantigen and indirect immunofluorescence antibody test (IFA) to identify serum antibodies against E. granulosus. From the analyzed dogs $7.7 \%$ (5/65) have presented the parasite in feces, $10.8 \%$ (7/65) had coproantigens and $13.8 \%$ (9/65) serum antibodies against this cestode. It was concluded that canine echinococcosis in the urban zone may represent a serious problem to public health, due to hidatidosis risk for humans.

\author{
Key words: Echinococcus granulosus, Dom Pedrito, \\ prevalence, urban stray dogs.
}

\section{INTRODUÇÃO}

A equinococose é uma infecção de canídeos pelas formas adultas dos tenídeos do gênero Echinococcus, helmintos de pequenas dimensões que vivem na luz do intestino delgado destes hospedeiros. Echinococcus granulosus (BATSCH, 1786) distribui-se de forma cosmopolita atingindo o homem e animais domésticos. Causa enfermidade nos hospedeiros da forma larvar, entidade denominada de hidatidose, zoonose de grande significado, que acarreta danos à saúde pública e perdas econômicas em diversas regiões do mundo, principalmente em zonas de pecuária. No estado do Rio Grande do Sul, tem como principais hospedeiros intermediários os bovinos e os ovinos, que asseguram a transmissão do helminto aos canídeos quando ingerem vísceras desses, contaminadas como cisto hidático. Desperta grande interesse nos países da América Latina, especialmente Uruguai, Argentina, Chile e Brasil (SCHANTZ, 1973; SANTOS, 1995; ANDERSEN et al., 1997).

Embora $\boldsymbol{E}$. granulosus tenha sido encontrado em vários carnívoros silvestres na América do Sul, o cão é o principal responsável pela disseminação da infecção hidática para os demais

\footnotetext{
${ }^{1}$ Médico Veterinário, Professor Substituto, Departamento de Microbiologia, Universidade Federal de Santa Maria (UFSM), Campus, 97105-900, Santa Maria, RS.

${ }^{2}$ Médico, Instituto de Higiene, Universidad de la República, Montevideo, Uruguay.

${ }^{3}$ Farmacêutico Bioquímico, Professor Titular, Departamento de Microbiologia, UFSM, Campus, 97105-900, Santa Maria, RS. E-mail: delarue@ccs.ufsm.br. Autor para correspondência
} 
animais domésticos e para o homem. A freqüência do cisto hidático pode ser diretamente relacionada com a prevalência da equinococose nos cães de determinada região (ACHA \& ZSYFRES, 1986; SANTOS, 1995).

Segundo FOGLIATTO \& PINOTTI (1967), SANTOS (1995) e SALGUEIRO (1995) no Brasil, o Rio Grande do Sul é o estado que apresenta as maiores taxas da infecção hidática nas espécies animais e no homem. Um total de 470 casos de hidatidose cística foram reportados no período de doze anos (1973-1984), neste estado, já que as condições para altas taxas de ocorrência tanto de equinococose como da hidatidose são propícias.

Relatos de NAQUIRA (1993) citam que a hidatidose é considerada uma doença rural, mas sua ocorrência em áreas urbanas tem sido significante devido à migração de cães afetados pelo $\boldsymbol{E}$. granulosus oriundos de áreas endêmicas. Na zona urbana, mesmo com cifras significativamente inferiores às da rural, a capacidade potencial do cão infectar o homem é muito superior em áreas de grande densidade demográfica. $\mathrm{O}$ grande êxodo rural traz consigo o risco da hidatidose, que se torna uma zoonose urbana. Desta forma, algumas zoonoses consideradas historicamente como rurais começam a apresentar uma elevada ocorrência nas cidades (ARAMBULO, 1997).

$\mathrm{Na}$ Argentina, mais precisamente na Patagônia, no período de 1984 e 1985, foi registrada uma prevalência de $1,12 \%$ de equinococose canina urbana (LARRIEU, et al., 1988). Conforme relatos de CARDOSO et al. (1995), na cidade de Melo (Uruguai), de $51 \%$ dos cães capturados no período de $8 / 9$ à 22/10 de 1992, em bairros urbanos e suburbanos, $4,4 \%$ eram portadores do parasita. Segundo ARAMBULO (1997), em Lima, a taxa de prevalência em cães urbanos infectados por $\boldsymbol{E}$. granulosus foi de $3,42 \%$ e de 48,2\% em Arequipa. Hábitos e costumes das pessoas que migram do meio rural para estes locais levam à manutenção do ciclo do parasita, através da alimentação dos cães com vísceras contendo cisto hidático.

A equinococose urbana assim como a rural têm grande importância, não só pelas perdas econômicas mas, principalmente, quando ocorre hidatidose acidental do homem. A infecção acidental pode ocorrer quando o homem mantém contato mais estrito com seus cães de estimação parasitados pelo cestódeo adulto, contraindo a infecção, pela ingestão de ovos de $\boldsymbol{E}$. granulosus por meio das mãos contaminadas, ou pela ingestão de alimentos ou água contendo ovos do parasita, oriundos das fezes destes cães fatores muitas vezes, aliados à higiene deficiente (REY, 1991).

Frente à carência de informações relativas à presença de $\boldsymbol{E}$. granulosus, o presente trabalho teve como objetivo verificar a prevalência deste parasita, em cães urbanos errantes da cidade de Dom Pedrito - RS, com o propósito de adequar as estratégias de controle para evitar a transmissão da equinococose/hidatidose na zona urbana.

\section{MATERIAL E MÉTODOS}

Este experimento foi conduzido no Biotério Central da Universidade Federal de Santa Maria. Foram analisados 65 cães urbanos errantes, oriundos do município de Dom Pedrito, zona endêmica do Rio Grande do Sul. Este município, de 40.000 habitantes, situando-se na fronteira com Uruguai, faz divisa com os municípios brasileiros de Santana do Livramento, Lavras do Sul e Bagé. Estes cães foram capturados nas ruas. Neste município, segundo dados da Inspetoria Veterinária (comunicação pessoal), há em torno de 5000 cães na área urbana, sendo que no ano de 1998 foram capturados 240 animais errantes. Foi empregada a técnica de purgação através de bromidrato de arecolina $^{1}$, para a identificação do parasita, o ensaio de imunoadsorção enzimática (ELISA), para detecção de coproantígenos e a técnica de imunofluorescência indireta (IFI), para documentar a resposta imunológica produzida por este cestódeo, através da sorologia, pela pesquisa de anticorpos contra o parasita adulto.

Para pesquisa de $\boldsymbol{E}$. granulosus nas amostras fecais dos cães, foi utilizada uma solução de bromidrato de arecolina à $1,5 \%$. Administrou-se $1 \mathrm{~m} \ell$ para cada $5 \mathrm{~kg}$ de peso do animal, equivalente a $3 \mathrm{mg} / \mathrm{kg}$ ( $15 \mathrm{mg}$ de bromidrato de arecolina por $\mathrm{m} \ell$ ). Coletou-se fezes com conteúdo mucoso, oriundas do intestino delgado, onde se determinou a presença de parasitas, através da observação direta das fezes sobre uma bandeja de fundo escuro com auxílio de um microscópio estereoscópico (SCHANTZ, 1973).

Para execução da técnica de IFI, primeiramente foram montadas lâminas com cortes do $\boldsymbol{E}$. granulosus processados em parafina, parasitas estes obtidos destes mesmos cães, através da técnica de purgação por bromidrato de arecolina. Segundo técnica de PROPHET et al. (1992), os parasitas utilizados para o corte foram fixados em formol $10 \%$ por 4 horas. Após, foram desidratados em sete álcoois; o primeiro e segundo álcool a 50\%, diluídos em água destilada, os demais álcoois são absolutos, utilizados para desidratação dos parasitas, por um período de 1 hora cada um dos mesmos. Em seguida, foram clarificados e desengordurados em xilol (PA), durante 1 hora. $\mathrm{O}$ passo seguinte foi a inclusão dos parasita em parafina a $65^{\circ} \mathrm{C}$ por 1 hora, para formar os blocos que foram utilizados para realizar os cortes do parasita, através do micrótomo, com espessura

Ciência Rural, v. 31, n. 5, 2001. 
média de 4 - $5 \mu \mathrm{m}$. Estes foram fixados sobre lâminas, colocadas em estufa a $60^{\circ} \mathrm{C}$ para fixação. Em seguida as lâminas com o corte passaram por xilol e álcool em várias concentrações $(96 \%, 90 \%$, $80 \%$ e $70 \%$ ) para remoção da parafina. As lâminas foram armazenadas a $-20^{\circ} \mathrm{C}$, de onde eram retiradas para execução da IFI. O anticorpo primário (soro sanguíneo) utilizado nesta técnica foi obtido de sangue, coletado por punção direta da veia safena de cada um dos cães a serem testados e posteriormente centrifugado. Este soro foi adicionado em diluição 1:2 sobre a lâmina contendo o corte do parasita, conforme técnica de PROPHET et al. (1992). Usouse como conjugado uma imunoglobulina de coelho anti-IgG de cão marcado com isotiocianato de fluoresceina (SIGMA) ${ }^{2}$ que foi previamente titulado, padronizando-se a diluíção a 1:60. A leitura foi realizada em microscópio de epifluorescência (ZEISS Axiolab HBO -50) em aumento de 400x. A reação antígeno-anticorpo foi considerada positiva quando o tegumento do corte do cestódeo, fixado em lâmina, apresentava-se com fluorescência verde maçã intensamente brilhante.

Para detecção de coproantígenos de $\boldsymbol{E}$. granulosus por meio do método ELISA, conforme instruções do fabricante do "kit" (Genzyme Virotech $)^{3}$, foram utilizadas fezes emitidas naturalmente pelos cães. A leitura foi realizada, em espectrofotômetro para microplacas sob o comprimento de onda de 450nm, obtendo-se os valores absolutos de absorbância em densidade óptica (DO). Valores estes empregados na fórmula determinada pelo fabricante do kit, por meio da qual identificaram-se as amostras positivas para presença de coproantígenos (valores >11), negativas (valores <9) e duvidosas (valores entre 9 - 11)

O tamanho da amostra foi calculado segundo BARBETA (1998), sendo que para as amostras foi utilizado o teste de "qui quadrado" $\left(\mathrm{x}^{2}\right)$, com um nível de significância de 5\% $(\mathrm{p}>0,05)$, através do pacote estatístico "Statistical Analysis System" (SAS) versão 6.08 (SAS Institute Inc., 1993).

\section{RESULTADO E DISCUSSÃO}

O primeiro aspecto analisado neste trabalho foi com relação à significância do tamanho da amostra de 65 cães em relação ao total de 240 cães errantes capturados anualmente no município de Dom Pedrito. Segundo análise estatística realizada para a amostra, esta demonstrou ser significativa.

No presente estudo, foi observado, através do teste de purgação pelo bromidrato de arecolina, a taxa de 7,7\% (5/65) da amostra de cães urbanos errantes, com a presença de $\boldsymbol{E}$. granulosus nas fezes (Tabela 1). No teste ELISA, foi detectado $10,8 \%$ (7/65) de cães urbanos errantes com a presença de coproantígenos nas fezes (Tabela 1) que provavelmente tinham $\boldsymbol{E}$. granulosus. Comparando estes dois métodos, percebe-se uma diferença na detecção da infecção em alguns cães parasitados com $\boldsymbol{E}$. granulosus, pois dois cães não foram sensíveis ao bromidrato de arecolina $\left(\mathrm{n}^{\circ} 18\right.$ e 50$)$, os quais apresentaram coproantígenos nas fezes.

Conforme GEMMELL \& ROBERTS (1998), a purgação por bromidrato de arecolina é um bom método de diagnóstico da equinococose canina, entretanto, este método tem problemas de baixa sensibilidade ( $25 \%$ dos cães não purgam), podendo não revelar a real prevalência. Além de ser intensamente laborioso, provoca efeitos colaterais nos cães tais como, vômito em $30 \%$ dos cães, convulsões e mal estar, não sendo indicado para animais idosos e fêmeas prenhes. Para realizar a técnica de purgação é preciso mais de uma pessoa, e as mesmas correm risco de contaminação.

Segundo NONAKA et al. (1996) e ECKERT \& DEPLAZES (1996), coproantígenos podem ser detectados tão logo o cão se infecte sendo possível a detecção a partir do quarto dia, decrescendo com o passar do tempo, o que pode sugerir uma expulsão contínua de pequenas quantidades de parasitas ou a redução na quantidade de antígenos produzidos pelos mesmos ou que ambos os fatos estejam ocorrendo simultaneamente. Este fenômeno explicaria as diferentes absorbâncias observadas no teste ELISA.

Apesar de não ter sido possível estabelecer uma comparação estatística entre as técnicas, observou-se que o método de detecção de coproantígenos pelo método de ELISA seria potencialmente a mais indicada para o uso em

Tabela 1 - Prevalência de Echinococcus granulosus em cães urbanos errantes do município de Dom Pedrito (RS), por meio do teste de purgação por bromidrato de arecolina e ensaio de imunoadsorção enzimática (ELISA).

\begin{tabular}{ccc}
\hline Cães & Bromidrato de arecolina & ELISA (DO) \\
\hline 18 & Neg & Pos $(0,827)$ \\
28 & Pos & Pos $(1,409)$ \\
29 & Pos & Pos $(0,820)$ \\
35 & Pos & Pos $(0,792)$ \\
39 & Pos & Pos $(0,890)$ \\
44 & Pos & Pos $(0,932)$ \\
50 & Neg & Pos $(0,998)$ \\
Total & 5 Positivas & 7 Positivas \\
\hline
\end{tabular}

Neg=Negativo

Pos $=$ Positivo

$\mathrm{DO}=$ Absorbancia 
levantamentos epidemiológicos, pela sua praticidade e sensibilidade, ao detectar um número maior de cães parasitados.

ECKERT \& DEPLAZES (1996) relatam que outra opção de identificação de infecção com $\boldsymbol{E}$. granulosus é pela demonstração da resposta imune específica do hospedeiro definitivo. Além deste ser um método de baixo custo, que pode ser empregado para discriminar uma população parasitada de uma não parasitada, de uma determinada área suspeita. Para a pesquisa de anticorpos no soro dos cães avaliados, empregou-se a diluição de 1:2 devido à baixa concentração de anticorpos circulantes, em razão da limitada resposta imunológica (TIZARD, 1998). Na tabela 2 observa-se que nove cães apresentaram anticorpos anti- $\boldsymbol{E}$. granulosus, sugerindo que devem ter tido contato prévio com o parasita, ou que estavam parasitados na ocasião da coleta. Esse dado representa uma taxa de 13,8\% dos cães com a presença de anticorpos séricos contra o cestódeo.

Somente dois cães $\left(n^{0} \quad 28\right.$ e 44$)$ apresentaram-se positivo para as três técnicas simultaneamente. Acredita-se que isto se deve à alta infestação por $\boldsymbol{E}$. granulosus que estes animais apresentavam, constatada pelo método de purgação associada a uma resposta imunológica eficiente. Conforme GASSER et al. (1994), ECKERT \& DEPLAZES (1996) e TIZARD (1998), níveis de anticorpos positivos em cães naturalmente infectados nem sempre refletem o atual grau de infecção ou número de parasitos do cão, assim como a ausência de anticorpos não isenta o animal de uma infecção inicial ou de falha no sistema imunológico quando se encontra com alta prevalência de infecção intestinal. Estes dados sugerem que, no presente trabalho, além dos nove cães positivos para presença de anticorpos anti-E. granulosus, poderia haver um

Tabela 2 - Avaliação de anticorpos séricos contra Echinococcus granulosus, Dipylidium caninum, Taenia hydatigena e Taenia ovis por meio do teste de imunofluorescência indireta.

\begin{tabular}{ccccc}
\hline Cães & E. granulosus & D. caninum & T. hydatigena & T. ovis \\
\hline 6 & Pos & Neg & Neg & Neg \\
11 & Pos & Neg & Neg & Neg \\
13 & Pos & Neg & Neg & Neg \\
28 & Pos & Neg & Neg & Neg \\
31 & Pos & Neg & Neg & Neg \\
44 & Pos & Neg & Neg & Neg \\
47 & Pos & Neg & Neg & Neg \\
62 & Pos & Neg & Neg & Neg \\
65 & Pos & Neg & Neg & Neg \\
Total & 9 Positivos & 0 & 0 & 0 \\
\hline
\end{tabular}

Neg $=$ Negativo

Pos $=$ Positivo número maior de cães que tiveram contato prévio com o parasita mas que não desenvolveram anticorpos, apresentando-se negativos pela IFI.

Anticorpos circulantes podem permanecer por várias semanas após a eliminação de $\boldsymbol{E}$. granulosus (CRAIG et al., 1995). O contrário é observado na detecção de coproantígeno que apresenta correlação entre a prevalência e intensidade de infecção intestinal por Echinococcus. Estudos de GASSER et al., 1994, relatam que alguns cães que se apresentaram negativos no teste de arecolina e sem a presença de parasitos na necropsia, foram soropositivos para anticorpos anti- $\boldsymbol{E}$. granulosus, sugerindo contato prévio com a infecção ou exposição ao parasita.

Nos resultados encontrados neste trabalho, não houve reação cruzada frente aos cestódeos de comum ocorrência nos cães da região, como Dipylidium caninum, Taenia hydatigena e Taenia ovis com E. granulosus, evidenciado através da reação negativa pela IFI, utilizando-se os mesmos soros frente a esses outros cestódeos.

Contudo, a contaminação dos cães deve estar ocorrendo pela ingestão de vísceras contaminadas com cisto hidático de carcaças de animais de abatedouros, ou de carcaças de animais que tiveram morte natural. Sabendo-se que a equinococose canina urbana oferece risco para hidatidose em humanos, sugere-se adoção das medidas de profilaxia e controle, neste local.

\section{CONCLUSÃO}

Diante dos resultados pode-se concluir que existe $\boldsymbol{E}$. granulosus em cães errantes da área urbana do município de Dom Pedrito.

\section{FONTES DE AQUISIÇÃO}

${ }^{1}$ Arecoline Hydrobromide - Sigma, St. Louis. Mo. USA ${ }^{2}$ FITC Conjugate Anti -Dog - Sigma, St. Louis. Mo. USA ${ }^{3}$ Genzyme Virotech - Löwenplatz 5, 65428 Rüsselsheim, Germany.

\section{REFERÊNCIAS BIBLIOGRÁFICAS}

ACHA, P.N., SZYFRES, B. Zoonoses y enfermedades transmisibles comunes al hombre y a los animales. 2 ed. Washington : OMS/OPS, 1986. 989p.

ANDERSEN, F.L., OUHELLI, H., KACHANI, M. Compendium on cystic echinococcosis in Africa and in Middle Eastern countries with special reference to Morocco. Provo Brigham, 1997. 345p.

ARAMBULO, P.III. Public health importance of cystic echinococcosis in Latin America. Acta Trop, v.67, p.113124, 1997.

Ciência Rural, v. 31, n. 5, 2001. 
BARBETA, P.A. A estatística aplicada às ciências sociais. 2 ed. Florianópolis : UFSC, 1998. 283p.

CARDOSO, M., SILVEIRA, C., ORLANDO, D., et al. Percentaje de Echinococcus granulosus y Taenia hydatigena en perros urbanos y suburbanos en la ciudad de Melo (necrópsia parasitária). In: JORNADA NACIONAL DE ACTUALIZACION CIENTIFICA EN HIDATATIDOSIS, 1995, Cerro Largo. Anais... Cerro Largo: Comisión Departamental Honararia de Lucha Contra la Hidatidosis de Cerro Largo, 1995. p31.

CRAIG, P.S., GASSER, R.B., PARADA, L., et al. Diagnosis of canine echinococcosis: comparison of coproantigen and serum antibody tests with arecoline purgation in Uruguay. Vet Parasitol, v.56, p.293-301, 1995

ECKERT, J., DEPLAZES, P. Methods for surveys on Echinococcus multilocularis infectios in final hosts. In: UCHINO, J., SATO, N. Alveolar echinococcosis: strategy for erradication of alveolar echinococcosis of the liver. Sapporo : Fujishoin, 1996. p.151-162.

FOGLIATTO, J., PINOTTI, H.W. Aspectos epidemiológicos da hidatidose humana no estado do Rio Grande do Sul (Brasil). Rev Inst Med Trop São Paulo, v.9, p.415-418, 1967.

GASSER, B.R., PARADA, L., ACUNA, A., et al Immunological assessment of exposure to Echinococcus granulosus in a rural dog population in Uruguay. Acta Trop, v.58, p.179-185, 1994

GEMMELL, M.A., ROBERTS, M.G. Cystic echinococcosis (Echinococcus granulosus). In: PALMER, S.R., SIMPSON, D.I.H. Zoonosis. New York : Oxford University, 1998. p. $665-689$

LARRIEU, E., IRIARTE, J., ZAVALETA, O. Aportes al conocimiento de la hidatidosis como zoonosis urbana. Rev Inst Med Trop São Paulo, v.30, n.1, p.28-31, 1988

NONAKA, N., IIDA, M., KINPEI, Y., et al. A diagnostic method for the difinitive host of Echinocccus multilocularis by coproantigen detection. In: UCHINO, J., SATO, N.
Alveolar echinococcosis: strategy for erradication of alveolar echinococcosis of the liver. Sapporo : Fujishoin, 1996. p.147-149.

NAQUIRA, C. Memorias de la reunión del grupo científico sobre avances en la prevención. control y tratamiento de la hidatidosis. Washington : Pan American Health Organization, 1993. Situación de la hidatidosis en Perú, 1993. p.217-229.

PROPHET, B.E., MILLSB., ARRINGTON, I.B., et al. Laboratory methods in histotechnology. Washington : American Registry of Pathology, 1992. 120p.

REY, L. Parasitologia. 2 ed. Rio de Janeiro : Guanabara Koogan, 1991. 731p.

SALGUEIRO, N. Memórias de la reunión del grupo científico sobre avances en la prevención. Control y tratamiento de la hidatidosis. Washington : Pan American Health Organization, 1995. Estado de la hidatidosis en Brasil: p.147-159

SAS, Institute. SAS ${ }^{\circledR}$ User's Guide: Statitics. Versão 6.08. 4. ed. Cary NC, 1993. p.956

SANTOS, H.T. Estudo da relação entre o uso do albendazole no tratamento da verminose ovina e o decréscimo da prevalência da hidatidose em ovinos e de Echinococcus granulosus em cães no município de Uruguaiana, Rio Grande do Sul, Brasil. Santa Maria, 1995. 65p. Dissertação (Mestrado em Medicina Veterinária) - Curso de Pós-graduação em Medicina Veterinária Preventiva, Universidade Federal de Santa Maria, 1995.

SCHANTZ, P.M. Guía para el empleo del bromhidrato de arecolina en el diagnóstico de la infección por Echinococcus granulosus en el perro. Boletín Chil Parasitología, v.28, p.81-90, 1973.

TIZARD, I. Imunologia veterinária. 5. ed. São Paulo : Roca, 1998. p.326-341

Ciência Rural, v. 31, n. 5, 2001. 